\title{
Safety profile of anti-TNF therapy in Crohn's disease management: a Brazilian single-center direct retrospective comparison between infliximab and adalimumab
}

\author{
Mariella BAU1', Patricia ZACHARIAS ${ }^{1}$, Diogo Araújo RIBEIR0 ${ }^{1}$, Larissa BOARON ${ }^{1}$, \\ Alvaro STECKERT FILHO² and Paulo Gustavo KOTZE ${ }^{1}$
}

Received 25/5/2017 Accepted 27/7/2017

\begin{abstract}
Background - Infliximab and adalimumab are considered effective drugs in the management of Crohn's disease. However, due to significant immunossupression, they can cause important adverse events, mostly infections. Objective - The aim of this study was to quantify and describe adverse events derived from adalimumab and infliximab use in Crohn's disease patients, and to compare the safety profile between these two agents. Methods This was an observational, single-center, longitudinal, retrospective study with Crohn's disease patients under infliximab or adalimumab therapy. Variables analyzed: demographic characteristics (including the Montreal classification), type of agent used, concomitant immunomodulators, presence and types of adverse events observed. Patients were allocated in two groups (infliximab and adalimumab) and had their adverse events accessed and subsequently compared. Results - A total of 130 patients were included (68 in infliximab and 62 in adalimumab groups, respectively). The groups were fully homogeneous in all baseline characteristics, with a median follow-up of $47.21 \pm 36.52$ months in the infliximab group and $47.79 \pm 35.09$ in the adalimumab group $(P=0.512)$. Adverse events were found in $43 / 68(63.2 \%)$ and 40/62 (64.5\%) in each group, respectively $(P=0.879)$. There were no differences between the groups regarding infections $(P=0.094)$ or treatment interruption $(P=0.091)$. There were higher rates of infusion reactions in the infliximab group $(P=0.016)$. Cephalea and injection site reactions were more prevalent in adalimumab patients. Conclusion - Adverse events were found in approximately two thirds of Crohn's disease patients under anti-TNF therapy, and there were no significant differences between infliximab or adalimumab.
\end{abstract}

HEADINGS - Crohn disease. Tumor necrosis factor-alpha. Infliximab, adverse effects. Adalimumab, adverse effects.

\section{INTRODUCTION}

Inflammatory bowel diseases (IBD) are complex disorders mainly comprised by Crohn's disease (CD) and ulcerative colitis $(\mathrm{UC})^{(17)}$. They were gathered on this same group for their resemblance: the pathogenesis based on a chronic bowel inflammation with undefined etiology ${ }^{(4)}$. Since these affections do not present chances of cure, IBD can be controlled by medical and, sometimes, surgical management ${ }^{(10)}$. The appropriate treatment choice is based on location, severity of presentation, response to drug therapy, and the presence of complications such as abscesses and fistulas ${ }^{(10,14)}$.

At first, patients were treated with corticosteroids and/or immunomodulators, but not all of them develop an adequate response to this primary therapy ${ }^{(9,10)}$. Since then, researchers were encouraged to develop new ways of controlling CD and UC. IBD management went through a major revolution when new classes of monoclonal antibodies, such as anti tumor necrosis factor (TNF) alpha agents, were described ${ }^{(1,2,6)}$.

TNF alpha is produced specially by macrophages and plays a key chore in orchestrating the inflammatory cascade. This com- pound must go through a three-level regulation to be released from macrophages, regarding the importance and intensity of its action ${ }^{(19)}$. Fever induction, insulin resistance, bone resorption, anemia and immune activation are some of the activities related to this pro-inflammatory cytokine ${ }^{(15,19)}$.

However, TNF alpha is not the only cytokine involved in the IBD pathogenesis. Other cytokines, such as IL-1, IL-6, IL-13 and TL1 $\alpha$ also have a well-defined participation in this process ${ }^{(17)}$. The organism's response to these proteins is crucial to the initiation, evolution and perpetuation of the inflammatory process that triggers $\mathrm{IBD}^{(18)}$.

Indeed, new drugs focused on TNF alpha inhibition have been developed to treat autoimmune affections and were successfully applied to CD management ${ }^{(1,8)}$. The efficacy of blocking the TNF in IBD was highly proved in both induction and maintenance of clinical response and remission ${ }^{(6,7,9,12,16)}$.

Currently, infliximab (IFX) and adalimumab (ADA) are the most used TNF alpha inhibitors in our country ${ }^{(11,12)}$. Certolizumab Pegol was recently approved for public reimbursement, and the experience with its use is still limited. Despite the effective control of

This article did not have any funding source.

Disclosure: PGK is a speaker and consultant for Abbvie, Ferring, Janssen, Pfizer and Takeda. All other authors have no disclosure.

Studied carried out at: Serviço de Coloproctologia do Hospital Universitário Cajuru - PUCPR (Curitiba - PR - Brasil).

${ }^{1}$ Unidade de Cirurgia Colorretal, Ambulatório de Doenças Inflamatórias Intestinais, Hospital Universitário Cajuru, Universidade Católica do Paraná, Curitiba, PR, Brasil; ${ }^{2}$ Cirurgia Colorretal, Gastro Medical Center, Florianópolis, SC, Brasil.

Correspondence: Paulo Gustavo Kotze. Rua Mauá, 682 - CEP: 80030-200 - Curitiba, PR, Brasil. pgkotze@hotmail.com 
inflammation, anti-TNF alpha agents are not innocuous drugs ${ }^{(3,13)}$. Numerous adverse events (AE) have been related to these medications, for instance: optic neuritis, exacerbation of multiple sclerosis and psoriasis, abscesses, opportunistic infections, upper respiratory tract infections, drug-induced lupus, arthralgia, allergic reaction, dermatitis and injection site reactions ${ }^{(4,5)}$. Concerning the occurrence of $\mathrm{AE}$ per agent, the safety profile is very similar between these drugs, and a class effect can be suggested. Nevertheless, there is a lack of Latin American studies that explore the safety findings and compare differences between ADA and IFX in the management of $\mathrm{CD}^{(11)}$.

The aim of this study was to quantify and describe AE derived from ADA and IFX use in CD patients, from a single-center cohort, and to compare the safety profile between these two agents. The secondary objectives were to analyze treatment discontinuation due to the occurrence of AE, as well as mortality during anti-TNF use.

\section{METHODS}

\section{Study design}

This was a longitudinal, retrospective observational study with CD patients treated with anti-TNF therapy from an IBD referral center from the South of Brazil, between January 2008 and April 2016.

\section{Inclusion and exclusion criteria}

Patients with an established diagnosis of CD by endoscopic, imaging and serological markers, those between 16 and 75 years of age and that used an anti-TNF agent (ADA or IFX) at any time of their disease management were considered for the study. Patients under 16 or over 75 years of age, those with undetermined IBD, with diagnosis of UC, treated with conventional therapy, without biologics, as well as those with lack of data and who were lost to follow-up were excluded from the analysis.

\section{Variables analyzed}

The following characteristics were included in the study protocol: age at diagnosis, age at anti-TNF initiation, Montreal classification (A: age at diagnosis; L: disease location and B: disease phenotype), disease duration (from diagnosis to anti-TNF initiation), smoking status, previous surgery due to $\mathrm{CD}$, perianal $\mathrm{CD}$, type of anti-TNF agent used, concomitant use of azathioprine (AZA) or 6-mercaptopurine (6-MP), time of follow-up on medication, treatment interruption and occurrence and detailed description of AE.

Patients were initially identified and selected from the IBD outpatient database from the Catholic University of Paraná, $\mathrm{Cu}-$ ritiba, Brazil. Electronic chart review was performed and a protocol with the variables of interest was fulfilled. Concurrently with data collection, comparative Excel charts were created embracing patients' main characteristics, mostly focusing on the presence and type of AE. Patients were allocated into two groups according to the anti-TNF agent used (IFX or ADA). The safety findings were then identified, quantified and subsequently compared between the two groups.

\section{Statistical analysis}

The statistical analysis included Pearson chi-square test and Mann-Whitney U test to verify group homogeneity (between IFX and ADA groups), in terms of baseline demographic and disease characteristics. The Student $t$ test was used to compare the frequency of each specific AE between the groups. $P$-values $<0.05$ were considered statistically significant. The analyses were performed with SPSS v23.0, IBM, Chicago, IL, USA.

\section{Ethical considerations}

The study protocol was approved by the Ethical Committee of Pontifícia Universidade Católica do Paraná in June/2016 (protocol number CAAE 56444316.3.0000.0020), under the Brazilian Ministry of Health website plataforma Brasil.

\section{RESULTS}

A total of 158 patients from the database were initially eligible. However, 19 patients were excluded due to final diagnosis of UC and nine patients due to lack of data in charts. Therefore, $130 \mathrm{CD}$ patients fulfilled the criteria for the analysis [68 (52.3\%) in the IFX and $62(47.7 \%)$ in the ADA groups, respectively]. The flowchart of the study sample is described in detail in Figure 1.

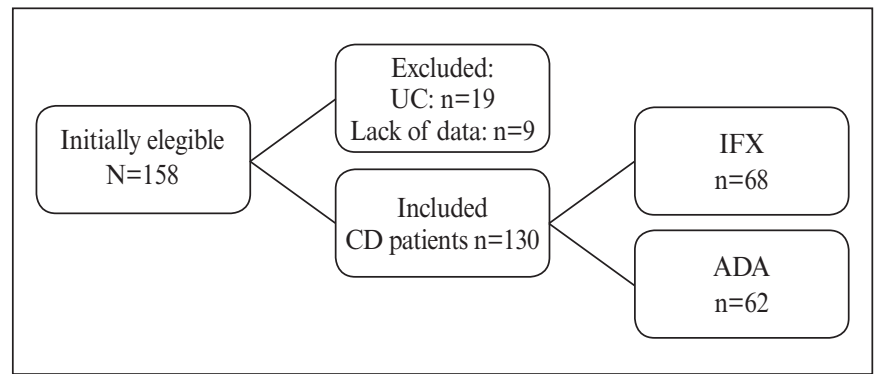

FIGURE 1. Flowchart of the study sample. In total, 130 patients comprised the population analyzed. IFX: infliximab; ADA: adalimumab.

The baseline characteristics of the patients are described in detail in Table 1. As seen, the population of the study was mostly composed by young patients, with a median disease duration of approximately 5 years, presenting with ileocolic location and inflammatory phenotype. Approximately $50 \%$ of the patients had perianal $\mathrm{CD}$, more than $80 \%$ were in combination therapy and one third had previous intestinal resections. There was no significant differences between the two groups in all variables analyzed, what made the groups fully comparable.

Regarding the primary objective of this study, AE were found in $63.2 \%$ of patients under IFX therapy and in $64.5 \%$ in those treated with $\operatorname{ADA}(P=0.879)$. These findings were observed during approximately 47 months of follow-up (average) in both groups.

The most common AE found in cohort were skin lesions, arthralgia, herpes virus and upper respiratory tract infections, as described in Table 2. Other less frequent AE are described in Table 3. Overall infectious adverse events occurred in $29.4 \%(20 / 68)$ in IFX and $43.5 \%(27 / 62)$ in ADA groups, respectively $(P=0.094)$. As seen in these interesting findings, a significant statistical difference was observed in the prevalence of infusion reactions $(P=0.016-$ more prevalent in IFX patients), cephalea $(P=0.004)$ and injection site reactions $(P=0.004)$, more prevalent in ADA patients.

Other rare but serious AE were also identified, such as peripheral neuropathy, leukocytoclastic vasculitis and optic neuritis. Four cases of tuberculosis were observed, three in the ADA group and one in the IFX group, all with negative screening tests before treatment initiation. In terms of malignancies, one case of hepatocellular carcinoma in a patient under ADA therapy was observed. 
TABLE 1. Baseline characteristics of the 130 included patients

\begin{tabular}{|c|c|c|c|}
\hline Variable & $\begin{array}{l}\text { IFX } \\
\mathrm{n}=68\end{array}$ & $\begin{array}{l}\text { ADA } \\
\mathrm{n}=62\end{array}$ & $P$ value \\
\hline Age at diagnosis (years) & $30.06( \pm 14.39)$ & $29.72( \pm 14.04)$ & 0.915 \\
\hline $\begin{array}{l}\text { Age at anti-TNF } \\
\text { initiation (years) }\end{array}$ & $35.60( \pm 15.21)$ & $35.65( \pm 13.71)$ & 0.807 \\
\hline Disease duration (years) & $5.75( \pm 5.85)$ & $5.95( \pm 6.53)$ & 0.989 \\
\hline Male gender (n/\%) & $37(54.4)$ & $25(40.3)$ & \multirow{2}{*}{0.108} \\
\hline Female gender (n/\%) & $31(45.6)$ & $37(59.7)$ & \\
\hline Smoking (n/\%) & $16(23.5)$ & $12(19.4)$ & 0.563 \\
\hline $\mathrm{A} 1(\mathrm{n} / \%)$ & $9(13.2)$ & $10(16.1)$ & \multirow{3}{*}{0.869} \\
\hline A2 (n/\%) & $43(63.2)$ & $39(62.9)$ & \\
\hline A3 $(\mathrm{n} / \%)$ & $16(23.5)$ & $13(21.0)$ & \\
\hline $\mathrm{L} 1(\mathrm{n} / \%)$ & $10(14.7)$ & $4(6.5)$ & \multirow{4}{*}{0.344} \\
\hline $\mathrm{L} 2(\mathrm{n} / \%)$ & $22(32.4)$ & $21(33.9)$ & \\
\hline $\mathrm{L} 3(\mathrm{n} / \%)$ & $36(52.9)$ & $36(58.1)$ & \\
\hline L4 (n/\%) & $0(0.0)$ & $1(1.6)$ & \\
\hline $\mathrm{B} 1(\mathrm{n} / \%)$ & $32(47.1)$ & $29(46.8)$ & \multirow{3}{*}{0.989} \\
\hline $\mathrm{B} 2(\mathrm{n} / \%)$ & $19(27.9)$ & $18(29.0)$ & \\
\hline B3 (n/\%) & $17(25.0)$ & $15(24.2)$ & \\
\hline $\begin{array}{l}\text { Perianal involvement } \\
(\mathrm{n} / \%)\end{array}$ & $34(50.0)$ & $35(56.5)$ & 0.462 \\
\hline $\begin{array}{l}\text { Concomitant } \\
\text { azathioprine/6-MP (n/\%) }\end{array}$ & $61(89.7)$ & $52(83.9)$ & 0.324 \\
\hline Previous resection $(\mathrm{n} / \%)$ & $27(39.7)$ & $22(35.5)$ & 0.620 \\
\hline $\begin{array}{l}\text { Median follow-up } \\
\text { (months) }\end{array}$ & $47.21( \pm 36.52)$ & $47.79( \pm 35.09)$ & 0.512 \\
\hline
\end{tabular}

Age at diagnosis, anti-TNF initiation, disease duration and time of follow-up analyzed with $U$ Mann-Whitney test. Other variables analyzed with the chi-square test. Quantitative variables with standard deviation $( \pm$ ). IFX: infliximab; ADA: adalimumab.

TABLE 2. Most common AE found in the cohort of patients

\begin{tabular}{lccc}
\hline $\begin{array}{l}\text { Adverse events (AE) }- \text { number of } \\
\text { patients }\end{array}$ & $\begin{array}{c}\text { IFX } \\
\mathbf{n}=68\end{array}$ & $\begin{array}{c}\text { ADA } \\
\mathbf{n}=62\end{array}$ & $\boldsymbol{P}$ value \\
\hline Skin lesions & 18 & 10 & 0.610 \\
Arthralgia & 14 & 14 & 0.785 \\
Infusion reactions & 6 & 0 & $0.016^{*}$ \\
Herpes virus infection & 6 & 9 & 0.314 \\
Upper respiratory tract infections & 5 & 4 & 0.841 \\
Cephalea & 0 & 7 & $0.004 *$ \\
Injection site reaction & 0 & 7 & $0.004 *$ \\
Moniliasis & 2 & 0 & 0.176 \\
Optic neuritis & 2 & 0 & 0.176 \\
Pneumonia & 2 & 0 & 0.176 \\
Sinusitis & 2 & 4 & 0.345 \\
Pseudomembranous colitis & 2 & 3 & 0.578 \\
Urinary tract infection & 1 & 4 & 0.142 \\
Tuberculosis & 1 & 3 & 0.270 \\
\hline
\end{tabular}

$* P<0.05$. IFX: infliximab; ADA: adalimumab.
TABLE 3. Less common AE found in the cohort of patients

\begin{tabular}{|c|c|c|c|}
\hline $\begin{array}{l}\text { Adverse event (AE) - number of } \\
\text { patients }\end{array}$ & $\begin{array}{l}\text { IFX } \\
\mathrm{n}=68\end{array}$ & $\begin{array}{l}\text { ADA } \\
\mathrm{n}=62\end{array}$ & $P$ value \\
\hline Infectious diarrhea & 1 & 0 & 0.342 \\
\hline Bacterial endocarditis & 1 & 0 & 0.342 \\
\hline Epididymitis & 1 & 0 & 0.342 \\
\hline Folliculitis & 1 & 0 & 0.342 \\
\hline Perianal HPV & 1 & 0 & 0.342 \\
\hline Onychomycosis & 1 & 0 & 0.342 \\
\hline Nausea & 1 & 0 & 0.342 \\
\hline Peripheral neuropathy & 1 & 0 & 0.342 \\
\hline Febrile neutropenia & 1 & 0 & 0.342 \\
\hline Intestinal perforation & 1 & 0 & 0.342 \\
\hline HBV reactivation & 1 & 0 & 0.342 \\
\hline Hordeolum & 1 & 2 & 0.509 \\
\hline Acne & 0 & 2 & 0.138 \\
\hline Soft tissue infection & 0 & 2 & 0.138 \\
\hline Tinea cruris & 0 & 2 & 0.138 \\
\hline Leukocytoclastic vasculitis & 0 & 2 & 0.138 \\
\hline Bartholinitis & 0 & 1 & 0.297 \\
\hline Recurrent vaginal candidiasis & 0 & 1 & 0.297 \\
\hline Facial and lower limb edema & 0 & 1 & 0.297 \\
\hline Hepatocellular carcinoma & 0 & 1 & 0.297 \\
\hline Hyperlipidemia & 0 & 1 & 0.297 \\
\hline Leukopenia & 0 & 1 & 0.297 \\
\hline
\end{tabular}

Regarding the secondary objectives of the study, treatment discontinuation was observed in $32.4 \%$ in the IFX group (22/68) and in $32.3 \%(20 / 62)$ in the ADA patients $(P=0.991)$. Only one patient died in this cohort, as a result of central permanent catheter infection and sepsis due to short bowel syndrome and total parenteral nutrition, during ADA treatment.

\section{DISCUSSION}

Anti-TNF agents constitute an effective therapy in the management of CD in general, but their systemic immunosuppression can be related to a myriad of adverse events. CD is usually being treated in young patients, and once a biological agent therapy is started, is not interrupted, unless severe AE do occur or secondary loss of response does not improve with therapeutic optimization. This means that patients usually are exposed to these agents for a significant period during their treatment.

There is a lack of studies regarding the safety profile of IFX and ADA in Latin American patients in the literature. Most of the data come from multicenter pivotal trials, as well as post marketing long-term studies that analyzed patients from different parts of the world $^{(5-7,9,13,14)}$. This study is one of the first to report a detailed safety profile of CD patients submitted to anti-TNF therapy in Brazil.

The population included in the analysis represents a typical sample of refractory CD patients from daily clinical practice: young individuals, with long disease duration presenting with luminal CD. Moreover, a significant proportion of our patients had perianal $\mathrm{CD}( \pm 50 \%)$ and was submitted to previous abdominal operations for intestinal resections (35\%-40\%), and this can be explained by the profile of our unit (surgeons treating medically IBD patients, a 
reality in some countries of the world like Brazil, Mexico, Colombia and Japan, for example).

Approximately two thirds of our patients developed at least one $\mathrm{AE}$ in both groups during a median follow-up of almost 4 years, $63.2 \%$ in IFX and $64.5 \%$ in ADA patients $(P=0.879)$. These numbers are in accordance with phase three studies for both agents (54.8\% to $65.81 \%$ in ADA trials ${ }^{(6)}$, up to $89 \%$ of IFX patients in the SONIC trial, for example) ${ }^{(7)}$. Comparative safety studies between agents are scarce in the literature, and we could not detect any difference in terms of prevalence of overall $\mathrm{AE}$ between the groups, what confirmed a previous study performed in the same unit, but with a smaller sample of patients ${ }^{(11)}$. Moreover, infectious $\mathrm{AE}$ in aggregation were also not different between the two groups [29.4\% (20/68) in IFX and 43.5\% (27/62) in ADA groups, respectively $(P=0.094)]$. These findings may suggest a class effect of anti-TNF agents in terms of safety in CD management. However, there is a clear need for a prospective study aiming to access this comparison.

Obviously, infusion reactions were more prevalent in the IFX group, $(P=0.016)$ and occurred in $6(8.8 \%)$ of the 68 patients. These findings are also comparable with data from other prospective studies $\left(6 \%\right.$ in the ACCENT I trial ${ }^{(9)}$ and $6.1 \%$ in the SONIC trial $\left.^{(7)}\right)$. Similarly, injection site reactions and pain were obviously more prevalent in the ADA group $(P=0.004)$ and occurred in 7 of the 62 patients (approximately 11\%). This rate was lower than other ADA studies, that reported injection site reactions in 2.6\%$5.5 \%$ of the patients ${ }^{(6)}$. Cephalea was also more prevalent in ADA patients, and was observed in 7/62 patients (11.2\%), while none of the IFX patients reported this $\operatorname{AE}(P=0.004)$. Headache can be described during anti-TNF therapy, and usually is not a cause for discontinuation of therapy ${ }^{(11)}$. In IFX patients, it can be associated frequently with infusion reactions.

Additionally, in this cohort of patients, several different AE were identified, as seen in Tables 2 and 3. This was probably due to the deeply detailed electronic chart review performed by a single researcher, what reduced the bias of data extraction and possibly increased the accuracy to detect AE.

The discontinuation of therapy lead by $\mathrm{AE}$ was also not different between the two groups in this cohort, $32.4 \%$ in the IFX and $32.3 \%$ in the ADA groups, respectively $(P=0.991)$. These numbers were higher than we expected for ADA, as other studies demonstrated lower frequency of treatment interruption. In a study with more than 3000 patients from the ADA programme for $\mathrm{CD}$, discontinuation was observed in $1.1 \%-6.3 \%$ of the patients ${ }^{(6)}$. On the other hand, the present numbers are comparable with data from other IFX studies, as the SONIC trial, where AE leading to discontinuation were observed in $17.8 \%-20.7 \%$ of the patients ${ }^{(7)}$.

There were only four cases of tuberculosis described in this cohort, despite adequate screening with chest $\mathrm{x}$-ray, detailed medical history and cutaneous reaction performed in all patients. These were probably cases of latent tuberculosis reactivation, and were all treated with proper antibiotics before resuming anti-TNF therapy, usually after 4-8 weeks after interruption.

Only one case of malignancy was detected in this group of patients, a 37 year-old man that was using ADA monotherapy and developed a hepatocellular carcinoma. The patient was submitted to partial liver resection, and as he was in deep remission for 2 years, a joint decision to interrupt $\mathrm{CD}$ therapy was made, and no direct relation between ADA and the tumor could be related. Malignancies are also rare findings in larger studies with anti-TNF therapy. The TREAT registry did not find any association between IFX and malignancies ${ }^{(13)}$. In the ADA programme, some cases of lymphoma and other non-melanoma skin cancers were described ${ }^{(6)}$, but they could be also related to the combined therapy with thiopurines. No cases of lymph proliferative disorders were observed in this cohort. Only one ADA patient died due to a severe central line sepsis, associated with malnutrition and combined immunosuppression.

This study has some limitations that must be clarified before interpretation of its results. First, the study was retrospective, and data collection can be always biased at some point, mainly due to the teaching hospital profile of our unit (several residents and students seeing the patients and making chart notes). Secondly, the study period was long (8 years) and the evolution of anti-TNF therapy was fast and remarkable over the years. This can reflect that in the beginning of the study period, detection of AE could be impaired, and improved in the last periods of the study duration, as the experience with these agents improved over the years. Additionally, AEs could be related to the immunomodulators and not to the anti-TNF agents. This difference is difficult to be clarified in a retrospective cohort study, but the proportion of patients in combination therapy was similar in both groups. Despite these limitations, the strength of this study is based on the fully homogeneous groups for comparison, what reflects the real life practice of our unit, using ADA and IFX in equal proportions and for similar patients.

In summary, this study demonstrated that approximately two thirds of CD patients under anti-TNF therapy develop an AE over time. Additionally, there was no significant difference in the prevalence and safety profile between those under IFX or ADA therapy. Infusion reactions were more prevalent in the IFX group, and injection site reactions and cephalea occurred more frequently in the ADA group. There was no difference in treatment discontinuation and mortality between the groups.

\section{Authors' contributions}

Kotze PG, Zacharias P and Bau M designed the study. Bau M did data collection. Kotze PG, Zacharias P, Ribeiro DA and Boaron $\mathrm{L}$ were involved in patient care. Steckert Filho A did the statistical analysis. Bau M and Kotze PG drafted the article and all authors gave final revision and permission for publication. 
Bau M, Zacharias P, Ribeiro DA, Boaron L, Steckert Filho A, Kotze PG. Perfil de segurança da terapia anti-TNF na doença de Crohn: um estudo observacional brasileiro comparativo entre infliximabe e adalimumabe. Arq Gastroenterol. 2017;54(4):328-32.

RESUMO - Contexto - A utilização de inibidores do fator de necrose tumoral (TNF) alfa no manejo da doença de Crohn é cada vez mais frequente. Tanto o infliximabe quanto o adalimumabe são considerados medicamentos efetivos no controle da doença. Entretanto, por serem potentes imunossupressores, podem causar efeitos adversos importantes, principalmente infecções. Objetivo - O objetivo primário deste estudo foi analisar a presença de efeitos adversos dos anti-TNFs em portadores de doença de Crohn, comparando-se infliximabe e adalimumabe e individualizando-se o perfil de segurança de cada droga. Métodos - Estudo observacional, longitudinal e retrospectivo, que incluiu portadores de doença de Crohn com uso de infliximabe ou adalimumabe de uma coorte de pacientes tratados em um único centro. Analisou-se características demográficas (incluindo-se a classificação de Montreal), tipo de agente utilizado, presença e tipo dos eventos adversos observados, entre outras variáveis. Os pacientes foram alocados em dois grupos (infliximabe e adalimumabe) e tiveram os efeitos adversos anotados e posteriormente comparados. Resultados - Um total de 130 pacientes foram incluídos ( 68 com infliximabe e 62 com adalimumabe). Os grupos foram homogêneos em todas as variáveis analisadas, com tempo de seguimento médio de 47,21 $\pm 36,52$ meses no grupo infliximabe e 47,79 $\pm 35,09$ no grupo adalimumabe $(P=0,512)$. Efeitos adversos foram encontrados em $43 / 68(63,2 \%)$ e 40/62 (64,5\%) nos dois grupos, respectivamente $(P=0,879)$. Não houve diferença entre os grupos em relação a infecções $(P=0,094)$ ou interrupção do tratamento $(P=0,091)$. Houve maiores índices de reações infusionais no grupo infliximabe $(P=0,016)$. Cefaleia e reações no local das injeções foram mais frequentes no grupo adalimumabe. Conclusão - Efeitos adversos foram encontrados em cerca de dois terços dos pacientes com doença de Crohn em uso de anti-TNF, não havendo maiores diferenças em relação ao uso de infliximabe ou adalimumabe.

DESCRITORES - Doença de Crohn. Fator de necrose tumoral alfa. Infliximab, efeitos adversos. Adalimumab, efeitos adversos.

\section{REFERENCES}

1. Armuzzi A, De Pascalis B, Fedeli P, De Vincentis F, Gasbarrini A. Infliximab in Crohn's disease: early and long-term treatment. Dig Liver Dis. 2008;40 (Suppl 2):S271-9.

2. Asgharpour A, Cheng J, Bickston SJ. Adalimumab treatment in Crohn's disease: an overview of long-term efficacy and safety in light of the EXTEND trial. Clin Exp Gastroenterol. 2013;6:153-160.

3. Atzori L, Mantovani L, Pinna AL, Pau M, Usai P. Cutaneous Adverse Reactions during Anti-Tnf Alpha Treatment for Inflammatory Bowel Diseases: The Experience of the Dermatology Clinic of Cagliari (Italy). J Pharmacovigilance. 2015, S2:004.

4. Baumgart D, Sandborn WJ. Crohn's disease. Lancet. 2012;380:1590-605.

5. Burmester GR, Panaccione R, Gordon KB, McIlraith MJ, Lacerda APM Adalimumab: long-term safety in 23458 patients from global clinical trials in rheumatoid arthritis, juvenile idiopathic arthritis, ankylosing spondylitis, psoriatic arthritis, psoriasis and Crohn's disease. Ann Rheum Dis. 2013;72:517-24.

6. Colombel JF, Sandborn WJ, Panaccione R, Robinson AM, Lau W, Li J, et al Adalimumab safety in global clinical trials of patients with Crohn's disease. Inflamm Bowel Dis. 2009;15:1308-19.

7. Colombel JF, Sandborn WJ, Reinisch W, Mantzaris GJ, Kornbluth A, Rachmilewitz D, et al. Infliximab, azathioprine, or combination therapy for Crohn's disease. N Engl J Med. 2010;362:1383-95.

8. Hamzaoglu H, Cooper J, Alsahli M. Safety of Infliximab in Crohn's Disease: A Large Single-center Experience. Inflamm Bowel Dis. 2010;16:2109-16.

9. Hanauer SB, Feagan BG, Lichtenstein GR, Mayer LF, Schreiber S, Colombel JF, et al. Maintenance infliximab for Crohn's disease: the ACCENT I randomised trial. Lancet. 2002;359:1541-9.
10. Hendy P, Hart A. A review of Crohn's disease. EMJ Gastroenterol. 2013;1: 116-23.

11. Kotze PG et al. Comparative analysis of adverse events between infliximab and adalimumab in Crohn's disease management: a Brazilian single-centre experience. J. Coloproctol. 2013;33:33-8

12. Kotze PG, Vieira A. Guia Prático de Terapia Biológica nas Doenças Inflamatórias Intestinais. São Paulo: Lippincott Williams \& Wilkins, 2010. p. 24-70.

13. Lichtenstein GR, Feagan BG, Cohen RD, Salzberg BA, Diamond RH, Langholff W, et al. Drug Therapies and the Risk of Malignancy in Crohn's Disease: Results from the TREAT Registry. Am J Gastroenterol. 2014;109:212-23.

14. Lichtenstein GR, Feagan BG, Cohen RD, Salzberg BA, Diamond RH, Price $\mathrm{S}$, et al. Serious Infection and Mortality in Patients With Crohn's Disease: More Than 5 Years of Follow-Up in the TREAT Registry. Am J Gastroenterol. 2012;107:1409-22.

15. Parameswaran N, Patial S. Tumor Necrosis Factor- $\alpha$ Signaling in Macrophages Crit Rev Eukaryot Gene Expr. 2010;20:87-103

16. Rubenstein JH, Chong RY, Cohen RD. Infliximab decreases resource use among patients with Crohn's Disease. J Clin Gastroenterol. 2002;35:151-6.

17. Sanchez-Muñoz F, Dominguez-Lopez A, Yamamoto-Furusho JK. Role of cytokines in inflammatory bowel disease. WJG. 2008;14:4280-8.

18. Strober W, Fuss IJ. Pro-Inflammatory Cytokines in the Pathogenesis of IBD Gastroenterology. 2011;140:1756-67.

19. Van Deventer SJ. Tumor necrosis factor and Crohn's disease. Gut. 1997;40 443-8. 